\title{
Iceberg of workplace violence in health sector of Bangladesh
}

\author{
Md Imran Hasan ${ }^{1 * \dagger}$, Md Zakiul Hassan ${ }^{2 \dagger}$, Md Mofijul Islam Bulbul $^{3}$, Taufique Joarder ${ }^{4,5}$ \\ and Mohammod Jobayer Chisti ${ }^{6}$
}

\begin{abstract}
Objectives: 'Negligence of Physicians' and 'Wrong Treatment' have become commonly-used phrases in print and electronic media of Bangladesh, while violence against healthcare workers has always been under-reported. Unfortunately, there is little evidence regarding physical violence against healthcare workers, while there is no data on the magnitude of psychological violence. The objective of this study was to quantify and explore the magnitude of workplace violence in health sector of Bangladesh to guide future research and adopt preventive policies.

Results: The Majority $(96 \%, n=54)$ of the violence cases were physical in nature and $91 \%$ violence $(n=51)$ took place in public healthcare settings. More than one-third (39\%) of the violence cases occurred at primary healthcare level and one-third (39\%) at tertiary healthcare level. It was mostly (61\%) the entry-level physicians who were affected by violence. The report reveals the tip of the iceberg of workplace violence in health sector of Bangladesh. Further studies should be undertaken to assess the prevalence, magnitude, and associated factors for workplace violence against healthcare workers.
\end{abstract}

Keywords: Iceberg, Workplace violence, Health sector, Healthcare worker, Bangladesh

\section{Introduction}

Workplace violence, either physical or psychological, has become a global problem crossing geographical borders, work settings, and occupational groups. While workplace violence affects practically all sectors and all categories of workers, the health sector is at major risk. Violence in this sector may constitute almost a quarter of all violence at work all over the world [1].

Under the eclipse of reforms, growing work pressure and stress, social instability and the deterioration of inter-personal relationships, workplace violence is rapidly spreading in the health sector. Recent studies confirm that workplace violence in the health sector is universal, although local characteristics may differ. Altogether it may affect more than half of the healthcare workers [2].

Workplace violence is prevalent in both developed and developing countries. In 2011, a national survey in the

\footnotetext{
*Correspondence: dr.imran.mmc@gmail.com

${ }^{\dagger}$ Md Imran Hasan and Md Zakiul Hassan contributed equally to this work

${ }^{1}$ Mymensingh Medical College, University of Dhaka, Dhaka, Bangladesh

Full list of author information is available at the end of the article
}

United States reported that $78 \%$ of the emergency medicine residents and attending physicians had experienced violence at the workplace [3]. In 1999, a study in Canada found that $68 \%$ of physicians reported an increased frequency of violence over time, and $60 \%$ reported an increased severity. $76 \%$ of the respondents witnessed verbal abuse, $86 \%$ witnessed physical threats or assaults and $57 \%$ were physically assaulted [4]. Researchers investigating workplace violence from European, Asian and Middle Eastern countries found a high prevalence of physical and psychological violence in the health sector of those countries [5-11].

Although healthcare providers are increasingly concerned about the escalating incidents of workplace violence, there is a lack of evidence to support this concern due to low reporting rates. A study found that only around $15 \%$ of workplace violence cases were reported to police or public security authorities [12]. In addition, sometimes these cases were reported as 'Negligence of Physicians' without proper investigation by the concerned authorities. The reported cases of violence form the tip of the iceberg while non-reported cases of 
violence remain as the submerged portion of the iceberg. Figure 1 shows conceptual framework of reported and not reported cases of workplace violence.

The negative consequences of such widespread violence affect heavily on the delivery of healthcare services, calling upon the quality of care. Besides, this is provoking the decision of the health workers to leave their professions. This, in turn, can result in a reduction in health services available to the general population, and an increase in health costs through defensive medical practice [1]. In developing countries like Bangladesh, equal access of care seekers to primary health care may be threatened if already scarce healthcare workers [13] abandon their profession because of the threat of violence [1].

Recently violence against the physician in Bangladesh has been increased and the severity has been intensified simultaneously. Along with emergency department, indoor departments also undergo violence either by patients or attendants of patients [14-17]. These eventually hamper the healthcare services for the innocent and poor patients.

Unfortunately, there is very limited data on violence against healthcare workers in Bangladesh. If we get an insight on the prevalence and associated factors of workplace violence, it will guide us to adopt preventive measures and workplace safety policies. The objective of this review was to explore the magnitude of workplace violence against healthcare workers to guide future research in identifying strategies that could effectively reduce the incidence of workplace violence in Bangladesh.

\section{Main text \\ Methods}

We surveyed an online newspaper named 'Platform' [18], which is published by a group of medical professionals that reports all news articles related to medical science and public health in Bangladesh. 'Platform' is run by "Platform Organization for Medical and Dental Society", which is a non-profit, non-political, non-government voluntary organization for physicians, medical and dental students of Bangladesh. It endeavors to provide an open platform for all medical personnel of Bangladesh contributing to various professional and social causes and offers a forum for peer-to-peer information sharing. Consequently, any violence against medical professionals in any corner of the country gets shared in the forum instantly and published online before other news media reports it.

'Platform' publishes news reports after several confirmations including both official and unofficial confirmation, i.e., peer confirmation. Therefore, we considered all reported news to be authentic. We assessed all the news articles that were published between May 2014 and

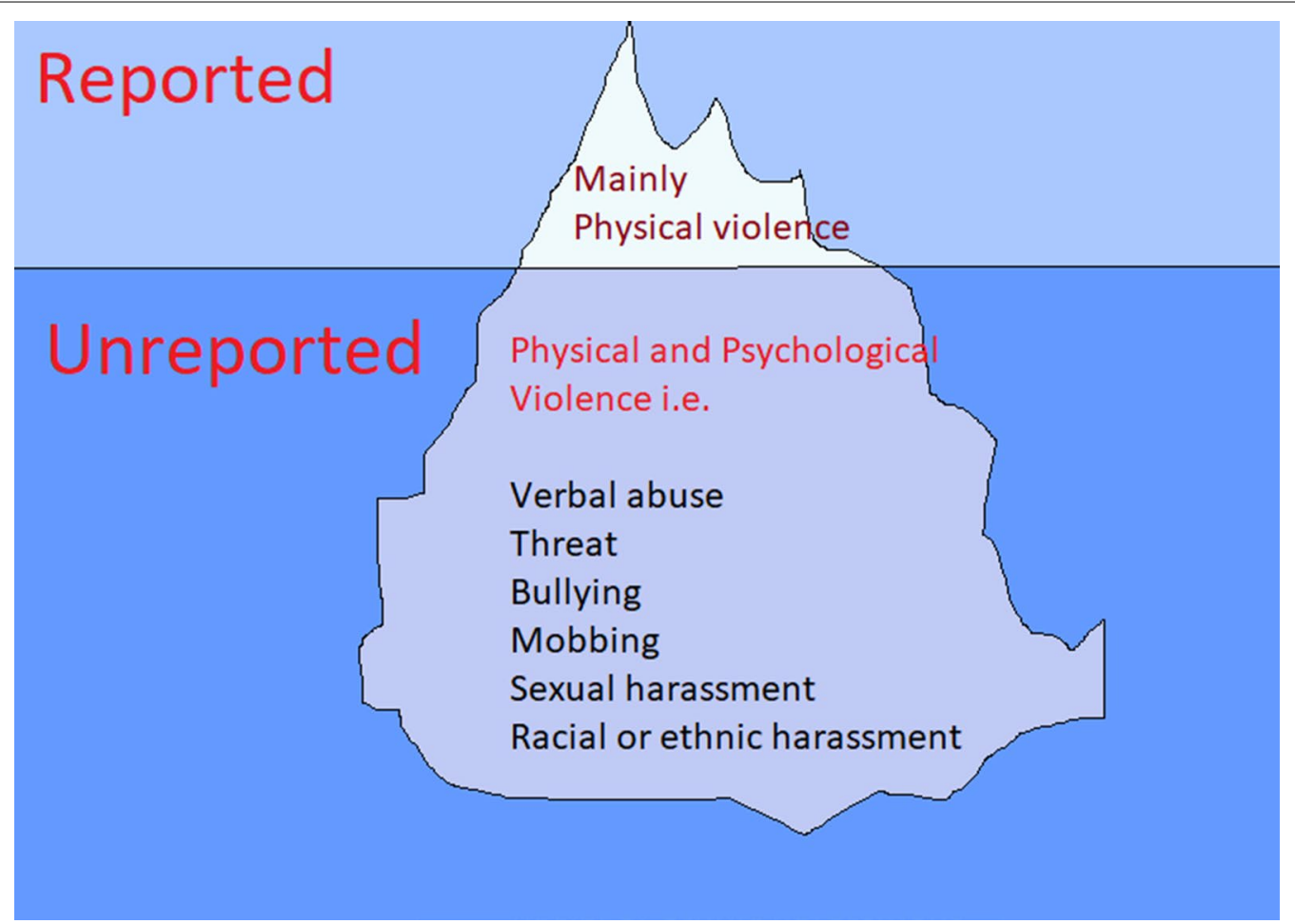

Fig. 1 Conceptual framework of iceberg of workplace violence in the health sector 
May 2017. Total 582 news articles were reviewed; among which 68 articles were identified for reporting violence against medical professionals. Multiple news for a single event was counted only once. Finally, 56 news articles were retrieved and incorporated into the database with the unique identification number in accordance with variables. The whole process was independently reviewed by two independent researchers and cross-matched subsequently. Contradictions between the two reviewers were solved by a third reviewer.

We identified variables from World Health Organization (WHO) guideline on workplace violence in health sector [19]. Identified variables were place of violence, type of healthcare setting, level of healthcare setting, department of healthcare setting, type of violence, professional category of the victim, immediate consequence of violence and follow up of violence. Two independent researchers conducted the content analysis of news articles and identified the selected variables. A third reviewer crosschecked and compiled the data and did descriptive analysis by using a statistical package SPSS, version 20.0.

Definitions and terms:

Classification of healthcare settings [20]:

- Primary: Sub-district level health centers (Upazilla Health Complex) and below, i.e. Union Sub-Centers and Community Clinics and equivalent private healthcare providers.

- Secondary: District level health centers (District Hospitals) and equivalent private healthcare providers.

- Tertiary: National Institutes, Medical Universities, Medical Colleges and equivalent private hospitals etc.

\section{Classification of healthcare providers:}

Most of the news articles reported violence against physicians, overlooking or underestimating violence against other healthcare workers. As physicians are directly related with treating patients and objected to violence, we only classified physicians according to existing hierarchy.

- Internship physician: Those who have passed final professional examination under a university and hold a provisional registration from Bangladesh Medical and Dental Council (BMDC).

- Entry-level physician: Those who work as House Officer or Medical Officer.

- Mid-level physician: Those who work as Assistant Registrar and Registrar.

- Consultant: Those who have completed post-graduation and work as Junior Consultant and Assistant Professor.
- Senior professional: Those who work as Senior Consultant or Associate Professor and above.

\section{Results}

The review revealed that incidents of violence against healthcare workers were distributed throughout the country, which is illustrated in Fig. 2. Around 91\% of violence took place at public healthcare centers. One-third of the violence $(39 \%)$ occurred at primary healthcare facilities and one-third (39\%) at tertiary healthcare facilities. Around $52 \%$ and $41 \%$ of violence were manifested at emergency and indoor department, respectively, while violence at the outdoor department was scarce. Of 56, 54 (96\%) reported cases of violence were physical in nature and two reports mentioned of psychological violence. Most of the reports $(n=54)$ covered violence against physicians. Entry-level physicians were the most affected group (61\%). One-third of violence led to strike and interruption of healthcare services. Most of the violence did not have a follow-up report or any update regarding intermediate and late consequences of that violence. Frequencies of workplace violence against healthcare workers in Bangladesh are summarized in Table 1.

\section{Discussion}

The study revealed that violence against health professionals was prevalent in all healthcare levels. No healthcare settings or professionals were immune to violence. All violence ended up in the strike, stoppage of services or other forms of health services distraction causing unbearable sufferings for the general service seekers, along with victims and offenders.

The study found 56 cases of violence within the threeyear period. It did not necessarily represent all violence at healthcare centers, rather a small portion of violence instead. Only cases of physical violence were reported, in some cases, under-reported. However, psychological violence was hardly reported. In a study, Gerberich et al. found that only $15 \%$ of the violence incidences in the health sector were reported [12]. Lack of administrative support, lengthy legal procedures, and fear of injustice contribute to low reporting of violence incidents in health sector [21].

Majority of the violence took place in primary and tertiary healthcare settings. Critical patients from rural areas first present at the primary health centers. Some of these patients deteriorate or die at primary centers, which may end up in violence. A study in the US also reported that working in the community settings was associated with violence [22]. Another study in Serbia reported that workplace violence prevailed in primary healthcare centers [23]. 


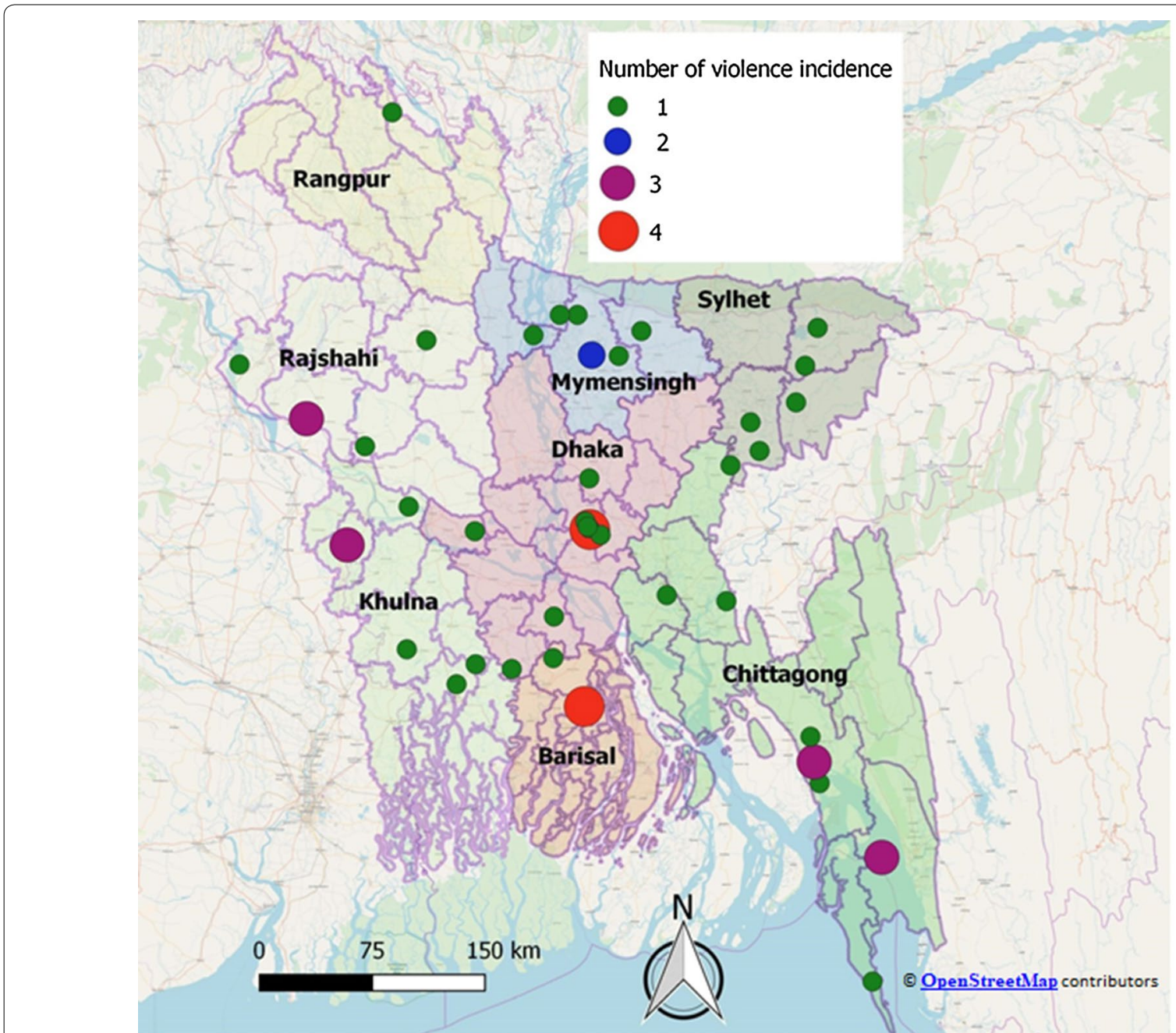

Fig. 2 Distribution of workplace violence in different health facilities by sub-districts (upazilla) of Bangladesh during May 2014-May 2017

As the health system of Bangladesh does not have a proper referral system, some of these critical patients get referred directly to tertiary centers bypassing the secondary healthcare facilities. Moreover, critical patients from urban and semi-urban areas visit tertiary the health centers directly. This practice causes huge workload on healthcare workers, and consultation time gets shortened. Eventually, it may lead to lack of patients' satisfaction followed by violence at tertiary healthcare centers. A study in Greece also reported a high prevalence of workplace violence at the tertiary hospital [7].

Around half of the reported physical violence took place at emergency departments. As emergency is the door of indoor departments, emergency department followed by the indoor department first deals critical patients. Some of these critical patients die either at emergency or indoor ward even after attending physicians' best efforts and these usually cause physical violence. Studies in different countries also emphasize that emergency departments are more vulnerable to experience physical violence [24-26].

This study showed that entry-level physicians were mostly affected by violence. Internship physicians and entry-level physicians are the preliminary and emergency service providers and patients get to see senior physicians after being stabilized. Therefore, interns and entry-level physicians are more prone to violence. Similarly, a study in the United States reported that age and years of experience were the risk factors for violence [22].

\section{Conclusions}

This study unveils the tip of the iceberg of workplace violence and guides to many research questions, e.g., the prevalence, magnitude, and possible risk factors for workplace violence against healthcare workers in Bangladesh. Further studies should be undertaken to assess 
Table 1 Different traits of reported workplace violence in health sector of Bangladesh between May 2014 and May, 2017

\begin{tabular}{|c|c|}
\hline Different traits of violence & Frequency (\%) \\
\hline \multicolumn{2}{|l|}{ Type of healthcare facility } \\
\hline Public & $51(91.1 \%)$ \\
\hline Private & $5(8.9 \%)$ \\
\hline \multicolumn{2}{|l|}{ Level of healthcare facility } \\
\hline Primary & $22(39.3 \%)$ \\
\hline Secondary & $12(21.4 \%)$ \\
\hline Tertiary & $22(39.3 \%)$ \\
\hline \multicolumn{2}{|l|}{ Department of healthcare facility } \\
\hline Emergency & $29(51.8 \%)$ \\
\hline Indoor & $23(41.1 \%)$ \\
\hline Outdoor & $2(3.6 \%)$ \\
\hline Other & $2(3.6 \%)$ \\
\hline \multicolumn{2}{|l|}{ Type of violence } \\
\hline Physical & $54(96.4 \%)$ \\
\hline Psychological & $2(3.6 \%)$ \\
\hline \multicolumn{2}{|l|}{ Professional category of victim } \\
\hline Physician & $54(96.4 \%)$ \\
\hline Nurse & $1(1.8 \%)$ \\
\hline Other & $1(1.8 \%)$ \\
\hline \multicolumn{2}{|l|}{ Professional status of victim } \\
\hline Internship physician & $9(16.1 \%)$ \\
\hline Entry level physician & $34(60.7 \%)$ \\
\hline Mid-level physician & $7(12.5 \%)$ \\
\hline Consultant & $2(3.7 \%)$ \\
\hline Senior professional & $2(3.7 \%)$ \\
\hline Other & $2(3.7 \%)$ \\
\hline \multicolumn{2}{|c|}{ Immediate consequence of violence } \\
\hline Strike & $17(30.4 \%)$ \\
\hline Peaceful protest & $15(26.8 \%)$ \\
\hline Stoppage of services & $5(8.9 \%)$ \\
\hline Law enforcement & $6(10.7 \%)$ \\
\hline Not reported & $13(23.2 \%)$ \\
\hline \multicolumn{2}{|l|}{ Follow up of violence } \\
\hline Yes & 2 (3.6\%) \\
\hline No & $54(96.4 \%)$ \\
\hline
\end{tabular}

and examine the consequences of violence, professionals' incident reporting patterns, and existing violence prevention and safety measures from healthcare workers' perspectives. As psychological violence was not reported or under-reported, longitudinal studies should be undertaken to investigate the depth of psychological violence. Similarly, violence against nurses and other supporting health staffs needs further investigations. The government should adopt workplace safety policy in the health sector, facilitate, and promote health services and health policy research to find innovative and cost-effective ways to combat this situation.

\section{Limitations}

There are several limitations in our review. First, despite our intention to conduct a comprehensive search for articles, it is possible for us still to miss some media reports on workplace violence on physicians. Second, we did not review the social media, e.g., Facebook, Twitter, etc., where there are extensive and informal discussions on workplace violence in the health sector. The breadth and volume of information on social media will definitely require a separate study and analysis.

\section{Abbreviations}

BMDC: Bangladesh Medical and Dental Council; SPSS: Statistical Package for the Social Sciences; US: United States; WHO: World Health Organization.

\section{Authors' contributions}

$\mathrm{MIH}, \mathrm{MZH}, \mathrm{MMIB}, \mathrm{TJ}, \mathrm{MJC}$ conceived and designed the study. MIH and MZH retrieved, incorporated and analyzed the data. MIH wrote the first draft. MJC, $\mathrm{TJ}, \mathrm{MZH}$ and MMIB wrote the second draft, critically reviewed, revised and finalized the manuscript. All authors read and approved the final manuscript.

\section{Author details}

${ }^{1}$ Mymensingh Medical College, University of Dhaka, Dhaka, Bangladesh. ${ }^{2}$ Sir Salimullah Medical College, University of Dhaka, Dhaka, Bangladesh. ${ }^{3}$ National Nutrition Services, Ministry of Health and Family Welfare, Dhaka, Bangladesh. ${ }^{4}$ Department of International Health (Health Systems), Johns Hopkins Bloomberg School of Public Health, Baltimore, MD, USA. ${ }^{5}$ FHI 360, Dhaka, Bangladesh. ${ }^{6}$ The University of Melbourne, Victoria, Australia.

\section{Acknowledgements}

The authors would like to thank Kafi MAH for producing the GIS map.

\section{Competing interests}

The authors declare that they have no competing interests.

\section{Availability of data and materials}

All news articles are supposed to be archived in the news portal referred in the methods section. The incorporated dataset can be available from corresponding author on reasonable request.

\section{Consent for publication}

Not applicable.

Ethics approval and consent to participate

Not applicable.

\section{Funding}

Not applicable.

\section{Publisher's Note}

Springer Nature remains neutral with regard to jurisdictional claims in published maps and institutional affiliations.

Received: 17 July 2018 Accepted: 26 September 2018

Published online: 04 October 2018 


\section{References}

1. ILO-ICN-WHO-PSI. Framework Guidelines for Addressing Workplace Violence in the Health Sector. 2002.

2. Di Martino V. Workplace Violence in the Health Sector: Country case studies: Brazil, Bulgaria, Lebanon, Portugal, South Africa, Thailand, and an Additional Australian Study. 2002.

3. Behnam M, Tillotson RD, Davis SM, Hobbs GR. Violence in the emergency department: a national survey of emergency medicine residents and attending physicians. J Emerg Med. 2011:40:565-79.

4. Fernandes CM, Bouthillette F, Raboud JM, Bullock L, Moore CF, Christenson JM, et al. Violence in the emergency department: a survey of health care workers. CMAJ. 1999;161:1245-8.

5. Franz S, Zeh A, Schablon A, Kuhnert S, Nienhaus A. Aggression and violence against health care workers in Germany - a cross sectional retrospective survey. BMC Health Serv Res. 2010;10:51.

6. Hegney D, Tuckett A, Parker D, Eley RM, Robinson L, MacLean S, et al. Workplace violence: differences in perceptions of nursing work between those exposed and those not exposed: a cross-sector analysis. Int J Nurs Pract. 2010;16:188-202.

7. Mantzouranis G, Fafliora E, Bampalis VG, Christopoulou I. Assessment and analysis of workplace violence in a Greek Tertiary Hospital. Arch Environ Occup Health. 2015;70:256-64.

8. Jiao M, Ning N, Li Y, Gao L, Cui Y, Sun H, et al. Workplace violence against nurses in Chinese hospitals: a cross-sectional survey. BMJ Open. 2015;5:e006719.

9. Sato K, Wakabayashi T, Kiyoshi-Teo H, Fukahori H. Factors associated with nurses' reporting of patients' aggressive behavior: a cross-sectional survey. Int J Nurs Stud. 2013;50:1368-76.

10. El-Gilany A-H, El-Wehady A, Amr M. Violence against primary health care workers in Al-Hassa, Saudi Arabia. J Interpers Violence. 2010;25:716-34.

11. Abbas MA, Fiala LA, Abdel Rahman AG, Fahim AE. Epidemiology of workplace violence against nursing staff in Ismailia Governorate, Egypt. J Egypt Public Health Assoc. 2010;85:29-43.

12. Gerberich S, Church T, McGovern P, Hansen H, Nachreiner N, Geisser M, et al. An epidemiological study of the magnitude and consequences of work related violence: the Minnesota Nurses'Study. Occup Environ Med. 2004;61:495-503.
13. Ahmed SM, Hossain MA, RajaChowdhury AM, Bhuiya AU. The health workforce crisis in Bangladesh: shortage, inappropriate skill-mix and inequitable distribution. Hum Resour Health. 2011;9:3.

14. DMCH interns call off strike. http://www.observerbd.com/detai Is.php?id=57397. Accessed 31 July 2017.

15. MMCH intern doctors go on indefinite strike. http://www.observerbd .com/2016/03/02/139360.php. Accessed 31 July 2017.

16. Bogra hospital interns continue strike for 3rd day. http://www.observerbd com/details.php?id=61759. Accessed 31 July 2017.

17. Belkuchi Health Complex closed. http://www.observerbd.com/detai Is.php?id=58685. Accessed 31 July 2017.

18. Platform. https://www.platform-med.org/category/news-event/. Accessed 31 May 2017

19. World Health Organisation. Joint programme on workplace violence in the health sector-questionnaire. Geneva: World Health Organisation; 2003.

20. Bangladesh Health System Review: Asia Pacific Observatory on Health Systems and Policies. 2015.

21. Gates DM. The epidemic of violence against healthcare workers. Occup Environ Med. 2004:61:649-50

22. Gillespie GL, Gates DM, Miller M, Howard PK. Workplace violence in healthcare settings: risk factors and protective strategies. Rehabil Nurs. 2010;35:177-84.

23. Fisekovic MB, Trajkovic GZ, Bjegovic-Mikanovic VM, Terzic-Supic ZJ. Does workplace violence exist in primary health care? Evidence from Serbia. Eur J Public Health. 2015;25:693-8.

24. Kowalenko T, Walters BL, Khare RK, Compton S. Workplace violence: a survey of emergency physicians in the state of Michigan. Ann Emerg Med. 2005:46:142-7.

25. Hamdan M, Abu Hamra A. Workplace violence towards workers in the emergency departments of Palestinian hospitals: a cross-sectional study. Hum Resour Health. 2015;13:28.

26. Ayranci U. Violence toward health care workers in emergency departments in west Turkey. J Emerg Med. 2005;28:361-5.
Ready to submit your research? Choose BMC and benefit from:

- fast, convenient online submission

- thorough peer review by experienced researchers in your field

- rapid publication on acceptance

- support for research data, including large and complex data types

- gold Open Access which fosters wider collaboration and increased citations

- maximum visibility for your research: over $100 \mathrm{M}$ website views per year

At $\mathrm{BMC}$, research is always in progress.

Learn more biomedcentral.com/submissions 